\title{
BMJ Global Health Falling aid for reproductive, maternal, newborn and child health in the lead-up to the COVID-19 pandemic
}

\author{
Catherine Pitt (D) , ${ }^{1}$ David Bath (D) , ${ }^{1}$ Peter Binyaruka (D) , ${ }^{2}$ Josephine Borghi (D) , \\ Melisa Martinez-Alvarez (10 ${ }^{3}$
}

To cite: Pitt C, Bath D, Binyaruka $P$, et al. Falling aid for reproductive, maternal, newborn and child health in the lead-up to the COVID-19 pandemic. BMJ Global Health 2021;6:e006089. doi:10.1136/ bmjgh-2021-006089

Handling editor Seye Abimbola

MM-A and JB are joint senior authors.

Received 22 April 2021 Accepted 21 May 2021

Check for updates

C Author(s) (or their employer(s)) 2021. Re-use permitted under CC BY. Published by BMJ.

${ }^{1}$ Department of Global Health and Development, London School of Hygiene \& Tropical Medicine, London, UK

${ }^{2}$ Department of Health System, Impact Evaluation and Policy, Ifakara Health Institute, Dar es Salaam, Tanzania ${ }^{3}$ Department of Global Health and Development, Medical Research Council Unit The Gambia at the London School of Hygiene \& Tropical Medicine, Dakar, Senegal

Correspondence to Dr Catherine Pitt; catherine.pitt@Ishtm.ac.uk

\section{INTRODUCTION}

Infectious disease epidemics pose a threat to reproductive, maternal, newborn and child health (RMNCH) both directly-by worsening women's and children's health outcomes-and indirectly-by reducing their access to services. ${ }^{1-4}$ Greater investment is therefore needed to mitigate the negative effects of COVID-19 and avoid a reversal of recent gains in $\mathrm{RMNCH}$ coverage and outcomes. ${ }^{1}$ However, COVID-19 has reduced household and government budgets, ${ }^{5}$ and there are concerns about the extent to which resources have been diverted away from $\mathrm{RMNCH}^{1}$

Alongside domestic government financing and household out-of-pocket expenditure, aid plays a substantial role in funding RMNCH services in many countries. In 2018, for example, aid accounted for $25 \%$ of current health expenditure in the 45 least developed countries. ${ }^{6}$ Across the 23 countries with RMNCH expenditure estimates for 2018, aid accounted for a median of $22 \%$ of $\mathrm{RMNCH}$ expenditure, ranging from $<1 \%$ in Namibia and the Seychelles up to $64 \%$ of child health and $84 \%$ of reproductive and maternal health expenditure in South Sudan. ${ }^{6}$ Yet, aid is volatile, ${ }^{7}$ subject to changing political priorities and not always responsive to needs. ${ }^{6}$ Global economic crises can lead to reduced aid levels and change the nature and sources of funding. ${ }^{8}$ Tracking disbursements of aid for RMNCH is therefore important for holding donors accountable for their commitments, including before, during and after crises.

\section{THE MUSKOKA2 METHOD FOR TRACKING AID FOR RMNCH}

The Muskoka2 method was previously developed to track aid for RMNCH as part of a collaboration between academics, donors and
Summary box

Greater investment in reproductive, maternal, newborn and child health (RMNCH) is needed to mitigate the negative effects of COVID-19 and avoid a reversal of recent gains in RMNCH coverage and outcomes.

- Aid for RMNCH as a whole fell by $6 \%$ between 2017 and 2018 and only increased by $2 \%$ in 2019; over the same 2-year period, aid for the reproductive health of non-pregnant women fell by $25 \%$.

- Volatile and falling aid for RMNCH may have rendered RMNCH systems more fragile in the 2 years preceding the COVID-19 pandemic.

- We encourage everyone-academics, advocates and policy makers - to explore and exploit the Muskoka2 aid for RMNCH dataset and other aid datasets, as part of efforts to improve RMNCH outcomes.

other stakeholders, including the Countdown to 2030 and the Partnership for Maternal Newborn \& Child Health. ${ }^{9}$ The Muskoka2 method was designed to enable the analysis of both donors' fulfilment of their commitments and the patterns of distribution of aid for RMNCH across recipients in a way that was efficient, timely, accurate, predictable and transparent. Muskoka2 sought to retain the simplicity and transparency of the original Muskoka approach, which was developed by G8 donors, while incorporating eight innovations to improve accuracy and enable more granular, recipient-level analyses by drawing on the strengths of the earlier Countdown to 2015 approach.

Muskoka2 is an algorithm applied to aid datasets maintained by the Organisation for Economic Cooperation and Development (OECD). The OECD datasets reflect aid reported by donors themselves in a comparable format, covering all development sectors. While the donors classify their 
reported aid by sector and subsectoral purpose, the categories do not permit straightforward estimates of aid for RMNCH. Conceptual and technical choices are therefore necessary to identify the share of total aid (to all sectors) to count within estimates of aid for RMNCH.

Consistent with the conceptualisation of RMNCH within the Every Woman Every Child Global Strategy, ${ }^{10}$ the Muskoka2 method seeks to estimate the monetary value of aid directly contributing to improvements in RMNCH outcomes. It therefore includes the full monetary value of aid categorised by donors as being directed towards reproductive health and family planning and includes relevant shares of aid directed towards HIV, malaria and other infectious diseases; health systems and basic healthcare; the humanitarian and water and sanitation sectors; and general budget support. The shares of aid for HIV, malaria, tuberculosis and general budget support counted towards RMNCH vary between recipient countries and over time to account for differences in demography, epidemiology and health spending. Muskoka2 is therefore suitable for use in analyses of the distribution of aid across recipient countries. Muskoka2 produces separate estimates of aid for maternal and newborn health, aid for the health of children aged 1-59 months and aid for the reproductive health of nonpregnant women.

We applied the Muskoka2 method to the most recent OECD datasets (January 2021 release). ${ }^{11}$ We included all disbursement data on official development assistance loans and grants and private development finance. To provide a picture of the aid landscape just before COVID-19 emerged, we present disbursements from the 48 donor countries, 35 multilateral institutions and 10 private donors reporting for both 2015 and 2019that is, across the 5 years leading up to the pandemic (figure 1) -and focus on changes since 2017, the year for which estimates of RMNCH aid were last published. ${ }^{9} 12$

\section{FALLING AID FOR RMNCH}

Aid for RMNCH fell by $6 \%$ from $\$ 16.7$ billion (constant 2018 US dollars) in 2017 to $\$ 15.6$ billion in 2018, and only increased by $2 \%$ in 2019 , to $\$ 15.9$ billion. In the same period, total aid for all sectors increased from $\$ 262$ billion in 2017 to $\$ 267$ billion in 2018 (2\%) and again by $2 \%$ in 2019 , reaching $\$ 273$ billion, indicating falling prioritisation of RMNCH.

The reduction in aid for RMNCH from 2017 to 2018 was largely driven by a collective decrease $(-18 \%$, $-\$ 643$ million) in disbursements from smaller donors (outside the top 10, see figure 1) and decreases by the USA ( $\$ 287$ million, $-5 \%)$, European Union (-\$198 million, $-29 \%)$ and Japan (-\$58 million, $-11 \%)$. From 2018 to 2019, the USA further decreased its aid for RMNCH (-\$1163 million, -20\%)-mostly through reductions in support for HIV/AIDS-as did the Netherlands ( $-\$ 77$ million, $-15 \%)$ and Canada ( $-\$ 46$ million, $-8 \%$ ). These 2018-2019 reductions were, however, offset by a $30 \%$ ( $\$ 1459$ million) increase in aid for RMNCH from multilateral institutions, notably UNICEF, GAVI, the Global Fund and United Nations Population Fund (UNFPA).

From 2017 to 2018, aid for child health, maternal and newborn health, and the reproductive health of nonpregnant women fell by $7 \%, 5 \%$ and $6 \%$, respectively. Over the 2-year period from 2017 to 2019 , however, aid for child health increased overall by $9 \%$ to $\$ 8.2$ billion and aid for maternal and newborn health increased by $2 \%$ to $\$ 3.2$ billion, whereas aid for the reproductive health of non-pregnant women fell by $25 \%$ to $\$ 4.2$ billion. Low-income countries collectively received an increasing share of aid for RMNCH (34\% in 2019), but the value of this aid fell from $\$ 5063$ million in 2017 to $\$ 4965$ million in $2018(-2 \%)$, before rising by $8 \%$ to $\$ 5363$ million in 2019.

\section{CHALLENGES IN TRACKING RESOURCE FLOWS FOR RMNCH}

These estimates are, of course, imperfect. Some donors, including China, do not report their aid to the OECD, so we may underestimate aid to some degree. ${ }^{13}$ Donors do not all report their aid entirely accurately, and there are substantial reporting delays; we will have to wait until early 2022 for the OECD to release sufficiently detailed disbursement data to estimate aid for RMNCH in 2020.

While the Muskoka2 method offers many advantages, it cannot estimate the contribution to RMNCH of individual projects and, as an algorithm, it inevitably involves simplifications and assumptions, which have been discussed in detail elsewhere. ${ }^{9}$ Muskoka2 does not produce disaggregated estimates of aid to family planning or newborn or adolescent health; key term searches and manual coding may be used to explore these and other areas within the data.

Two other approaches are used to track aid for RMNCH in quite different ways. ${ }^{14}$ One approach, the RMNCH policy marker, is implemented by donors themselves within the OECD's aid activities database. Donors are asked to code each aid activity they report according to whether it fully, partially or does not support RMNCH. The approach is thus not designed to produce estimates of aid for RMNCH and donors report inconsistently, limiting its usefulness for aid tracking, despite the apparent advantages of individually categorising each aid activity. ${ }^{14}$ The Institute for Health Metrics and Evaluation (IHME) produces estimates of development assistance for health, which it disaggregates by health area, including reproductive and maternal health and neonatal and child health. ${ }^{15}$ IHME's approach includes key term searches to categorise activities directed towards RMNCH, excluding aid directed towards infectious diseases, the health system or the humanitarian or water and sanitation sectors; it is applied to a combination of OECD disbursement data, other data sources and projections for more recent years. 


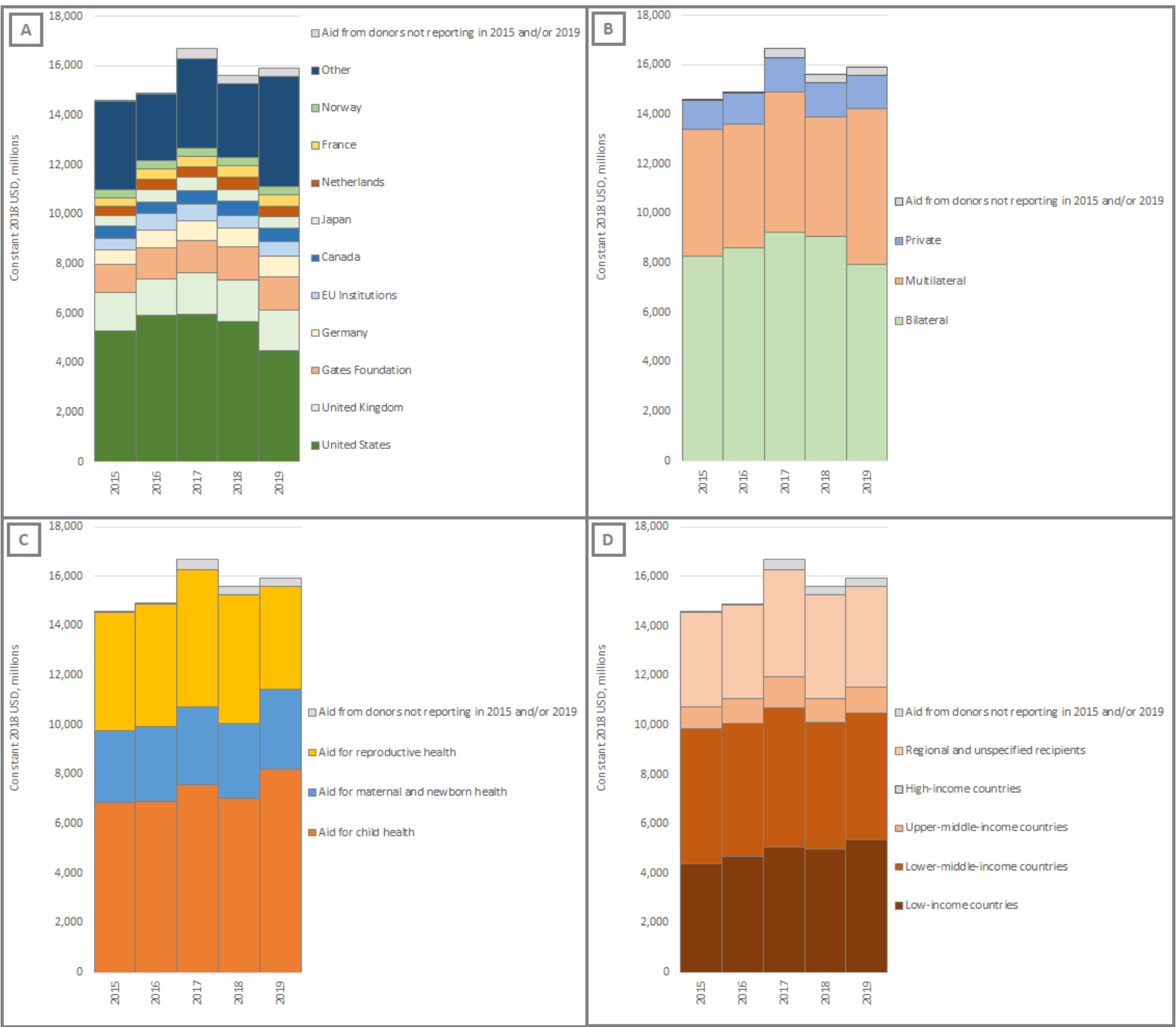

Figure 1 Trends in aid for RMNCH, 2015-2019. Values cited in the text are restricted to donors reporting in both 2015 and 2019 to avoid reporting bias in trends over time, as some donors did not report in all years. Panels show trends in aid for $\mathrm{RMNCH}$ : (A) disaggregated by donor, including both direct bilateral disbursements and core contributions to multilateral institutions from the top 10 largest donors over the time period and other bilateral and private donors; (B) disaggregated by type of donor deciding the purpose and recipient of the disbursement; $(\mathrm{C})$ disaggregated by aid for child health, for maternal and newborn health and for the reproductive health of non-pregnant women; and (D) disaggregated by the World Bank country income group classification for recipient countries and regional and unspecified recipients. EU, European Union; RMNCH, reproductive, maternal, newborn and child health; USD, United States dollars.

None of these aid tracking methods can currently be used to analyse domestic financing for RMNCH, which is a crucial component of the overall RMNCH resource envelope. Assessment of whether reductions in aid are offset by increases in domestic financing would be valuable; however, estimates of domestic financing for RMNCH are only available for selected years for selected low-income and middle-income countries ${ }^{1617}$ and are very resource and time intensive to produce. ${ }^{18} 19$ With the Countdown to 2030 , we are working to develop a Muskoka2-style algorithm that can be used to track domestic allocations to RMNCH in a timely and transparent manner.

\section{CONCLUSION}

While the Muskoka2 estimates published in 2020 painted a hopeful picture of a $10 \%$ increase in aid for RMNCH from 2016 to $2017,,^{9}$ our updated findings, with two more years of data, are worrying. Our findings suggest that volatile and falling RMNCH investments may have rendered RMNCH systems more fragile in the 2 years preceding 
the COVID-19 pandemic. If World Bank predictions of falling overall global aid levels in $2021-2025^{20}$ are correct, health and RMNCH in particular would need to be increasingly prioritised just to maintain recent RMNCH aid levels. A slight increase in the US global health aid is expected in 2021-2022, ${ }^{21}$ but the U-the second largest bilateral donor-has announced substantial cuts to the health and humanitarian sectors. ${ }^{22}$ In both countries, new commitments to COVID-19 and 'global health security' $^{21} 22$ within stagnant or shrinking health aid budgets risk crowding out RMNCH at a time when more, not less investment is needed.

We present only the geographic and demographic destinations of aid; however, many other analyses are possible with these data. We therefore encourage everyone academics, advocates and policy makersto explore and exploit the Muskoka2 aid for RMNCH dataset,${ }^{12}$ as well as the wider OECD aid datasets. ${ }^{11}$ Future work should further explore measures of aid effectiveness, including the channels through which RMNCH funds are disbursed, ${ }^{723}$ and equity in the allocation and distribution of RMNCH aid. ${ }^{16}$ Such analyses are crucial to guide advocacy efforts to improve RMNCH outcomes, especially in low-income countries.

Twitter Catherine Pitt @catkpitt, David Bath @davidjbath, Peter Binyaruka @peter_binyaruka, Josephine Borghi @JosephineBorghi and Melisa MartinezAlvarez @Melisa_MarAl

Contributors $\mathrm{CP}$ drafted the text with MM-A and JB. DB managed the data. CP and $\mathrm{DB}$ analysed the data. All authors revised and approved the final version.

Funding This study was funded by the Bill and Melinda Gates Foundation (INV007594) via the Countdown to 2030.

Competing interests None declared.

Patient consent for publication Not required.

Provenance and peer review Not commissioned; externally peer reviewed.

Data availability statement Data are available in a public, open access repository: https://datacompass.Ishtm.ac.uk/id/eprint/2272/.

Open access This is an open access article distributed in accordance with the Creative Commons Attribution 4.0 Unported (CC BY 4.0) license, which permits others to copy, redistribute, remix, transform and build upon this work for any purpose, provided the original work is properly cited, a link to the licence is given, and indication of whether changes were made. See: https://creativecommons.org/ licenses/by/4.0/.

\section{ORCID iDs}

Catherine Pitt http://orcid.org/0000-0003-4967-8966

David Bath http://orcid.org/0000-0001-7742-7721

Peter Binyaruka http://orcid.org/0000-0002-1892-7985

Josephine Borghi http://orcid.org/0000-0002-0482-5451

Melisa Martinez-Alvarez http://orcid.org/0000-0003-4020-7527

\section{REFERENCES}

1 Graham WJ, Afolabi B, Benova L, et al. Protecting hard-won gains for mothers and newborns in low-income and middle-income countries in the face of COVID-19: call for a service safety net. BMJ Glob Health 2020;5:e002754.

2 Semaan A, Audet C, Huysmans E, et al. Voices from the frontline: findings from a thematic analysis of a rapid online global survey of maternal and newborn health professionals facing the COVID-19 pandemic. BMJ Glob Health 2020;5:e002967.

3 Sochas L, Channon AA, Nam S. Counting indirect crisis-related deaths in the context of a low-resilience health system: the case of maternal and neonatal health during the Ebola epidemic in Sierra Leone. Health Policy Plan 2017;32:iii32-9.

4 Roberton T, Carter ED, Chou VB, et al. Early estimates of the indirect effects of the COVID-19 pandemic on maternal and child mortality in low-income and middle-income countries: a modelling study. Lancet Glob Health 2020;8:e901-8.

5 IMF. World economic outlook update. 2021. Washington: International Monetary Fund, 2021.

6 WHO. Global health expenditure database. Geneva: World Health Organization, 2021.

7 Martinez-Alvarez M, Acharya A, Arregoces L, et al. Trends in the alignment and harmonization of reproductive, maternal, newborn, and child health funding, 2008-13. Health Aff 2017;36:1876-86.

8 Leach-Kemon K, Chou DP, Schneider MT, et al. The global financial crisis has led to a slowdown in growth of funding to improve health in many developing countries. Health Aff 2012;31:228-35.

9 Dingle A, Schäferhoff M, Borghi J, et al. Estimates of aid for reproductive, maternal, newborn, and child health: findings from application of the Muskoka2 method, 2002-17. Lancet Glob Health 2020;8:e374-86.

10 Every Woman Every Child. The global strategy for women's, children's and adolescents' health (2016-2030). Geneva: Every Woman Every Child, 2015.

11 OECD. Creditor reporting system. organization for economic cooperation and development, 2021.

12 Countdown to 2030 Health Financing Data Analysis Center. Muskoka2 global dataset: aid for reproductive, maternal, newborn, and child health, 2002-2019. London: LSHTM DataCompass, 2021.

13 Micah AE, Zhao Y, Chen CS, et al. Tracking development assistance for health from China, 2007-2017. BMJ Glob Health 2019;4:e001513.

14 Pitt C, Grollman C, Martinez-Alvarez M, et al. Tracking aid for global health goals: a systematic comparison of four approaches applied to reproductive, maternal, newborn, and child health. Lancet Glob Health 2018;6:e859-74.

15 Global Burden of Disease Health Financing Collaborator Network. Health sector spending and spending on HIV/AIDS, tuberculosis, and malaria, and development assistance for health: progress towards sustainable development goal 3. Lancet 2020;396:693-724.

16 Martinez-Alvarez M, Federspiel F, Singh NS, et al. Equity of resource flows for reproductive, maternal, newborn, and child health: are those most in need being left behind? BMJ 2020;368:m305.

17 Mann C, Ng C, Akseer N, et al. Countdown to 2015 country case studies: what can analysis of national health financing contribute to understanding MDG 4 and 5 progress? BMC Public Health 2016;16 Suppl 2:792.

18 Pradhan J, Sidze EM, Khanna A, et al. Mapping of reproductive health financing: methodological challenges. Sex Reprod Healthc 2014;5:90-8.

19 Price JA, Guinness L, Irava W, et al. How to do (or not to do) ... translation of national health accounts data to evidence for policy making in a low resourced setting. Health Policy Plan 2016;31:472-81.

20 Kurowski C, Evans DB, Tandon A. From double shock to double recovery - Implications and options for health financing in the time of COVID-19. Washington, DC: World Bank Group, 2021.

21 Kates J, Michaud J. What will be the contours of the Biden Administration's global health agenda? Washington, DC: Kaiser Family Foundation, 2021.

22 Foreign, Commonwealth \& Development Office. UK official development assistance (ODA) allocations 2021 to 2022: written ministerial statement. London, 2021.

23 Erondu NA, Aniebo I, Kyobutungi C, et al. Open letter to international funders of science and development in Africa. Nat Med 2021;27:742-4. 